\title{
Avalanche situation in Turkey and back calculation of selected events
}

\author{
A. Aydın ${ }^{1}$, Y. Bühler ${ }^{2}$, M. Christen ${ }^{2}$, and I. Gürer ${ }^{3}$ \\ ${ }^{1}$ Düzce University Faculty of Forestry, Konuralp Campus, 81620 Düzce, Turkey \\ ${ }^{2}$ WSL Institute for Snow and Avalanche Research SLF, Flüelastrasse 11, 7260 Davos Dorf, Switzerland \\ ${ }^{3}$ Professor Emeritus, Gazi University Faculty of Engineering Civil Engineering Department, Maltepe 06570 Ankara, Turkey
}

Correspondence to: A. Aydın (aaydin@duzce.edu.tr)

Received: 24 December 2013 - Published in Nat. Hazards Earth Syst. Sci. Discuss.: 21 January 2014

Revised: - - Accepted: 8 April 2014 - Published: 19 May 2014

\begin{abstract}
In Turkey, an average of 24 people die in snow avalanches every year, mainly in the eastern part of Anatolia and in the eastern Black Sea region, where high-mountain ranges are close to the sea. The proportion of people killed in buildings is very high (87\%), especially in comparison to other European countries and North America. In this paper we discuss avalanche occurrence, the climatic situation and historical avalanche events in Turkey; in addition, we identify bottlenecks and suggest solutions to tackle avalanche problems. Furthermore, we have applied the numerical avalanche simulation software RAMMS (rapid mass movements simulation) combined with a (digital elevation model) DEMbased potential release zone identification algorithm to analyze the catastrophic avalanche events in the villages of Üzengili (Bayburt province) in 1993 and Yaylaönü (Trabzon province) in 1981. The results demonstrate the value of such an approach for regions with poor avalanche databases, enabling the calculation of different scenarios and the estimation of run-out distances, impact pressure and flow height.
\end{abstract}

\section{Introduction}

Mountain ranges can provide valuable resources such as minerals, recreational services, wood for fuel and building material, and special agricultural products (Kräuchi et al., 2000). They are also an important source of water (Viviroli et al., 2007). However, mountain environments, due to their harsh topography and climatic conditions, are subject to natural hazards such as landslides, debris flows, rockfalls, flash floods and snow avalanches. Mountain areas occupy about one-fourth of the total land surface on earth and are home to about $1 / 10$ of all human beings (Ives et al., 1997; Price and Butt, 2000). Seventy-eight percent of Turkey's land surface consists of mountains, with 33.4 million people (about $47 \%$ of the country's total population) living in these regions (EEA, 2010).

Turkey in general is comprised of two peninsulas, Thrace and Anatolia, with a 2-D area of $769471 \mathrm{~km}^{2}$, excluding lakes (Elibüyük and Yılmaz, 2010). This present landform was created by the convergence of Tethys Sea sediments located among the African, Eurasian and Arabian plates. Thus, Alpine orogeny began with this convergence and has continued up to present day (Bozkurt, 2001). Therefore, Turkey has been tectonically active, and this has directly affected the character of its landforms and determined its aspect, slope and elevation features. Mountain ranges run in a west-east direction, parallel to the Black Sea in the north and to the Mediterranean Sea in the south. Comparatively high mountains (e.g., the Ağrì Mountain at $5165 \mathrm{~m}$ and the Reşko summit of Cilo Mountain at $4168 \mathrm{~m}$ ) and plains (e.g., the Doğu Beyazıt plateau at $2000 \mathrm{~m}$ and the Erzurum plateau at $1900 \mathrm{~m}$ ) exist at the eastern part of the Anatolian peninsula (Fig. 1). According to a recent study (Elibüyük and Yılmaz, 2010), the mean altitude of Turkey is $1141 \mathrm{~m}$ a.s.l., more than three times higher that of Europe ( $300 \mathrm{~m}$ a.s.l.), with a mean slope angle of $10^{\circ}$. Altitudes higher than $1500 \mathrm{~m}$ with slopes greater than $27^{\circ}$ cover $5.1 \%$ of the total area. These values dramatically increase in the eastern Black Sea region, which has been identified as a hotspot for avalanches. The average altitude and average slope of the eastern Black Sea area are $1662 \mathrm{~m}$ a.s.l. and $19^{\circ}$, respectively. The elevation of $66 \%$ of 


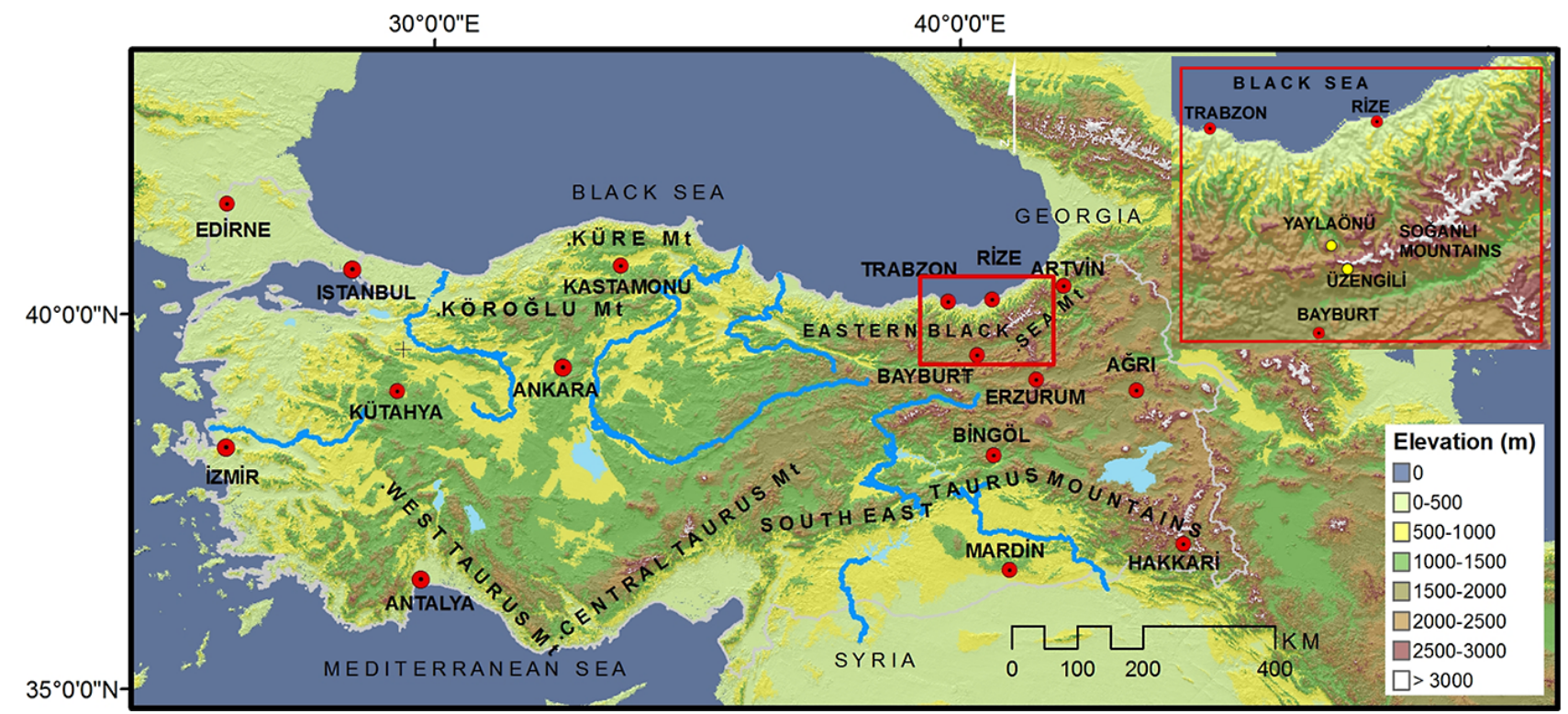

Fig. 1. Physical map of Turkey showing the most important mountain ranges and study areas (upper right corner).

the total land surface is higher than $1500 \mathrm{~m}$ a.s.l. and $22.6 \%$ of all the slopes are steeper than $27^{\circ}$ (Elibüyük and Y1lmaz, 2010). Altitudes higher than $1500 \mathrm{~m}$ with slopes greater than $27^{\circ}$ cover $12 \%$ of the total eastern Black Sea region (ErkanY1lmaz, 2012, personal communication, see Fig. 1).

Even though avalanches are a serious issue in Turkey, the management of snow avalanches has not yet attracted the necessary attention. According to a new regulation, the office of mountainous areas management (MAM), organized under the Turkish Forest Service, was established in 2011. This new office is mainly responsible for the prevention of floods, snow avalanches and landslides, and for preparing hazard and risk maps. Before the establishment of this office, the avalanche team (AT) of the General Directorate of Disaster Affairs (GDDA) was responsible for this task. The AT was established after the destructive 1992-1993 avalanche cycle in Turkey and had undertaken various national and international projects (Gürer, 1998). Because of the recent reorganization, this team was abolished and all staff members were transferred to various other departments. This discontinuity has been a big drawback to setting up an institutional memory and years of accumulated experience have been lost. Due to the vagueness of the duties and responsibilities of the MAM, no avalanche events have been recorded since the AT was abolished in 2009. The MAM office is located in central Ankara and as of yet has no branch offices in local avalanche-prone areas. When avalanches occur, there is at present no one responsible for recording and documenting the events, drawing outlines or making necessary measurements and analyses. Therefore, only a few recorded events are available, and there is no updated avalanche database in place today in Turkey.
Snow and avalanche mitigation profits substantially from research and development (R\&D) organizations such as the WSL Institute for Snow and Avalanche Research SLF in Switzerland and the National Research Institute of Science and Technology for Environment and Agriculture (IRSTEA, formerly CEMAGREF) in France. Continuity in research, determining the needs and gaps in research and practice, and increasing the quality of practical measures are some of the main aims of such institutions. In Turkey there are no such research institutes, resulting in a lack of support for practitioners and capacity building in the country.

Even though the MAM is responsible for the hazard and risk mapping of natural hazards in Turkey, no guidelines or regulations exist to define the process of hazard and risk mapping; therefore, there are no restrictions on land use. As a result, buildings, tourism facilities and traffic infrastructures are still being constructed in high-risk avalanche zones in Turkey.

In Turkey weather stations are operated by the State Meteorological Office (SMO). Almost all stations are located in city centers, which do not represent the high-mountain ranges or places far from the cities where the avalanches occur. Furthermore, the total amount of snow and rainfall precipitation as measured by the gauges is not differentiated. The quality and scarcity of this meteorological data make them nearly meritless for analyzing avalanche events.

The aim of the present paper is to describe the meteorological and avalanche situation in Turkey and to assess the applicability of a dynamic avalanche simulation model (RAMMS - rapid mass movements simulation) to back calculate two well-documented events. 


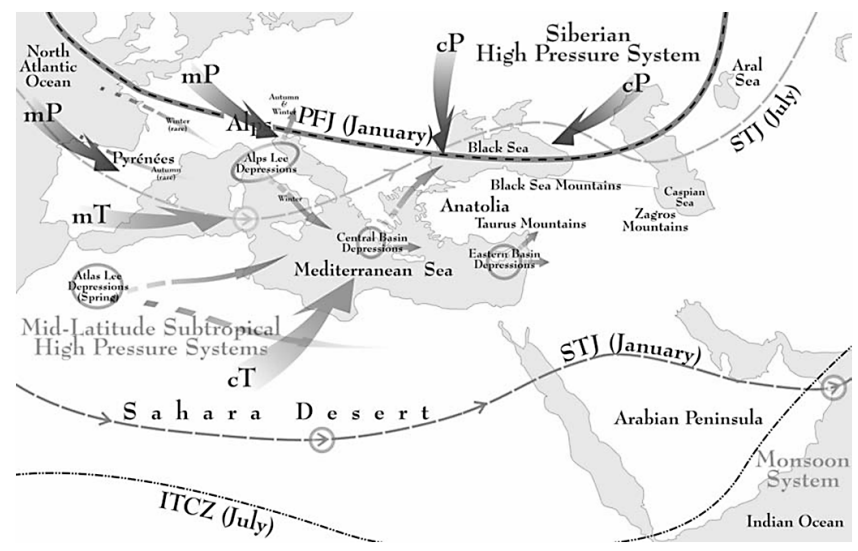

Fig. 2. Air masses affecting Turkey (Akçar and Schlüchter, 2005).

\section{Climatic situation}

In winter, Turkey is usually under the influence of polar air masses, classified as maritime polar (mP) and continental polar (cP). Maritime polar air masses originate in the Atlantic Ocean and pass over Europe from NW to SE (Fig. 2). They bring rainfall to the Black Sea coast and snow to the inland region. Continental polar air masses originate in Siberia and are very cold and dry. When they pass over the Black Sea, they become moister and can cause orographic rainfall in the Black Sea coastal zone. When $\mathrm{cP}$ air masses reach the Mediterranean region, they get warmer and gain moisture, resulting in thunderstorms. The Mediterranean and Black Sea mountain ranges run parallel to the coasts. This topography causes significant differences in climate from one region to another. While coastal areas have a milder climate, the high-mountain hinterlands of the coasts receive high amounts (2-3 m) of snowfall (Gürer and Naaim, 1993), and the inland Anatolian plateau experiences cold winters with limited precipitation, for example, $443 \mathrm{~mm}$ in Bayburt and $407.5 \mathrm{~mm}$ in Erzurum (Sensoy, 2004; Akçar and Schlüchter, 2005; Bekereci et al., 2010). The orographic effects in both the Taurus and Black Sea mountains are dominant. For instance, in the eastern Black Sea region rainfall sharply decreases from coastal Rize, with a mean annual precipitation of $2200 \mathrm{~mm}$, to the inland eastern Anatolian city of Erzurum, $130 \mathrm{~km}$ to the south, with mean annual precipitation of $407.5 \mathrm{~mm}$. Both cities are situated north of the Mediterranean climate boundary (Akçar and Schlüchter, 2005).

\section{Avalanche history}

Historically, avalanches have occurred mainly in the eastern Black Sea region, in eastern Anatolia, in the mountainous part of the south-eastern region of Anatolia, and, last but not least, in high and/or steep-sloped mountainous areas in the rest of the country (Fig. 3). Avalanche fatalities are high in Turkey, with an average of 24 lives lost per year. Between

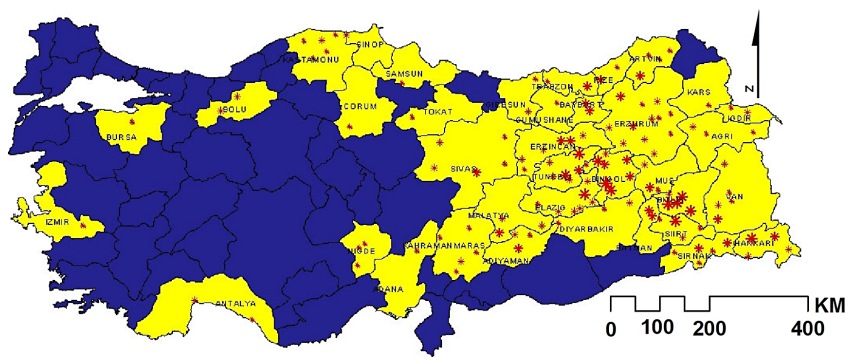

Fig. 3. Avalanche record map of Turkey (yellow color refers avalanche observed cities and red stars refer to recorded avalanche locations, Source: GDDA).

1951 and 2006, 676 avalanches were recorded in the Turkish avalanche archives, with a total of 1325 fatalities and 365 injured (GDDA, 2009). Most of these accidents took place in the eastern and south-eastern parts of the Anatolian peninsula (Fig. 3). Out of the 1325 deaths, $120(9 \%)$ were soldiers, $27(2 \%)$ were hunters, $18(1.4 \%)$ were skiers and climbers, $12(0.9 \%)$ were buried in cars on highways, one $(0.08 \%)$ was a worker; the remaining $1147(86.6 \%)$ were local inhabitants trapped in their houses. About onethird of all recorded avalanches occurred in villages in the Trabzon, Rize and Bayburt provinces of the eastern Black Sea region of Turkey (see Fig. 1). During field visits to the eastern Anatolian and eastern Black Sea regions of Turkey, and after interviewing local people, we realized that the numbers in the archives seem to be significantly lower than the real numbers in terms of both casualties and avalanche occurrences. Avalanche statistics demonstrate that avalanches in Turkey mainly affect settlements. In contrast, in the European Alps and in North America, most casualties result from winter sport activities. For instance, in Switzerland for the winter seasons of 1987-1988 to 1996-1997, the average number of avalanche fatalities was 22.9 per year and, $90 \%$ of these were related to recreational activities (Schweizer and Lütschg 2001); fatalities due to recreational activities were 22.45 per year for the winter seasons of 1970-1971 to 20092010 (Zweifel et al. 2012). Similarly, in the United States, recreational activities accounted for $96 \%$ of all avalanche fatalities from 1999-2000 through 2008-2009 (Atkins 2010). In recent years winter tourism has also gained importance in Turkey, and the casualties have been increasing accordingly. As an example, on 25 January 2009 an avalanche in Zigana pass in Trabzon province in Turkey's eastern Black Sea region buried 17 mountaineers, 10 of whom lost their lives. Similarly, on 11 February 200614 mountaineers were buried by an avalanche at Demirkazik summit in the Aladağlar Mountains of the central Anatolian region with four fatalities. During very extreme winter conditions, avalanches can occur at new locations where no avalanches have been observed before. On 25 and 30 December 1992 in two events in the Kastamonu province of western Black Sea region of 
Turkey, 13 people were killed, two injured and 17 houses damaged (Gürer et al., 1995). The altitude of the starting zone of one of these avalanches (Kayaarkasiavalanche) was located as low as approximately $900 \mathrm{~m}$ a.s.l. (Köse et al., 2010). Due to scarcity of avalanche data and the unavailability of an avalanche database in Turkey, we selected only the two best documented and studied avalanche events, in order to back calculate them with the avalanche dynamic simulation model of RAMMS. Thus, the 1993 Üzengili (Bayburt province) avalanche, documented in several publications (Gürer and Naaim, 1993; Gürer et al., 1993), and the 1981 Yaylaönü (Trabzon province) avalanche, where data was collected in the field and affected people interviewed by two of the authors, were selected for this study. Furthermore, these cases are located in the Bayburt-Rize-Trabzon triangle, a site accounting for one-third of all recorded avalanches in Turkey.

\section{Study area}

This study was conducted in two different survey areas (Üzengili and Yaylaönü) in order to back calculate the observed and documented avalanche events. Üzengili village is located at $40^{\circ} 23^{\prime} 00^{\prime \prime} \mathrm{E}-40^{\circ} 29^{\prime} 30^{\prime \prime} \mathrm{N}$ and is $41 \mathrm{~km}$ north of the Bayburt city center (Fig. 1). The village is located in the lee direction of the Soğanlì Mountains in the eastern Black Sea region of Turkey. The altitude of the village is $1950 \mathrm{~m}$ a.s.l. and it is in a downstream area of bowlshaped slopes. Yaylaönü village is located at $40^{\circ} 18^{\prime} 00^{\prime \prime} \mathrm{E}-$ $40^{\circ} 35^{\prime} 15^{\prime \prime} \mathrm{N}$ and $105 \mathrm{~km}$ south-east of the Trabzon city center (Fig. 1). The village is located in the northern part of the Soğanlì Mountains in the eastern Black Sea region of Turkey at an altitude of 1700-1900 m a.s.l., at the edge of the central section of an avalanche track.

For this study, we generated DEM data sets from $10 \mathrm{~m}$ contour interval and 1:25000 scaled topographical maps. We generated raster data of the study area with a grid resolution of $10 \mathrm{~m}$ as input for the numerical simulations with RAMMS. Reference information on the events was obtained by interviewing affected people and, consulting photographs, newspaper articles and archives of official institutions.

\subsection{The 1993 Üzengili avalanche}

The Üzengili avalanche path consists of an open bowl in the upper part, a channeled track and an open run-out zone with slopes of $7^{\circ}-10^{\circ}$ (Fig. 6). Both, the release and the run-out zones were sparsely vegetated with small bushes. The 1993 avalanche stopped about $500 \mathrm{~m}$ before the bottom of the valley. A brief description of the Üzengili avalanche and information on deposition height (at the center of the debris about 8-10 m) can be found in Gürer and Naaim (1993). A sketch (Fig. 9) by the GDDA describing the location of damaged buildings and mosque were given and it is assumed

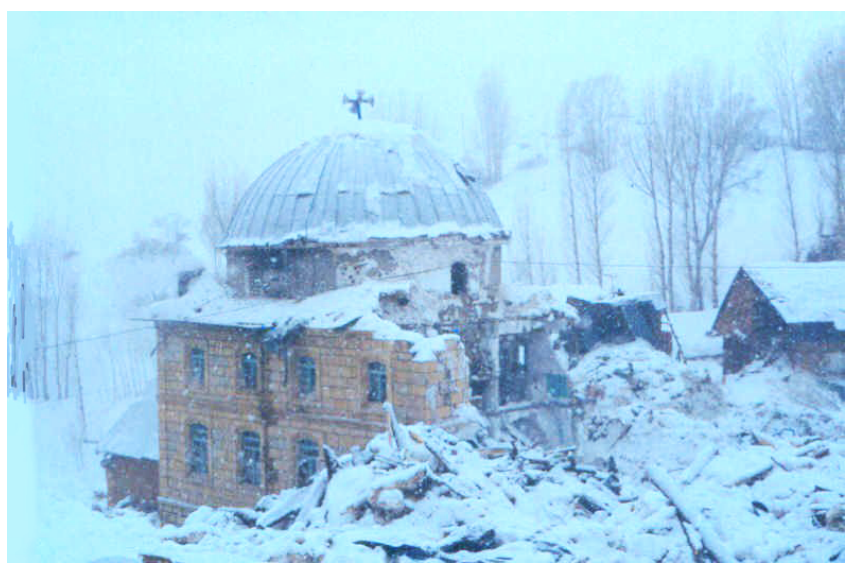

Fig. 4. Destroyed mosque due to 1993 avalanche event in Üzengili village.

that this sketch shows the boundary of the avalanche. Information on building damage and a collection of observations from local people were taken from GDDA archives. All residential structures had been constructed from bricks and wooden material. Only mosque had been constructed of masonry. Release depth estimation was done based on Gürer and Naaim (1993) and statements from villagers and finally we use $160 \mathrm{~cm}$ for the model.

The avalanche mass started from the high part of the mountain on 18 January 1993 at 7:30 a.m. and buried 85 houses, 72 of which were completely destroyed or transported to the far end of the run-out zone (Fig. 4). Fifty-nine people were killed and 21 injured. Prior to the avalanche release, new snow had fallen continuously for a period of three days, with heavy northern winds which brought $70 \mathrm{~cm}$ of fresh and dry snow; the air temperature had consistently remained at well-below zero (Gürer and Naaim, 1993). The villagers inferred that the first avalanche had come from the slope on the orographic left-hand side (the release zone of this avalanche is visible for the villager), filling the channel with snow deposits. Just a few minutes later, a second avalanche came from the slope on the right-hand side (this release zone is invisible for the villager) and flowed over the previously filled channel, destroying large parts of the village. People mentioned a past avalanche which had occurred around 1890, in which 10 houses disappeared. Other than this information, no one living there could remember any other avalanches.

\subsection{The 1981 Yaylaönü avalanche}

In total four avalanches were recorded in Yaylaönü village. The first recorded avalanche occurred in 1850 s, a second in 1974, a third in 1981 and the last in 1993. The 1850s event killed three people and destroyed three houses (constructed from bricks and wooden material), whereas the 1981 avalanche destroyed three houses (constructed from bricks 


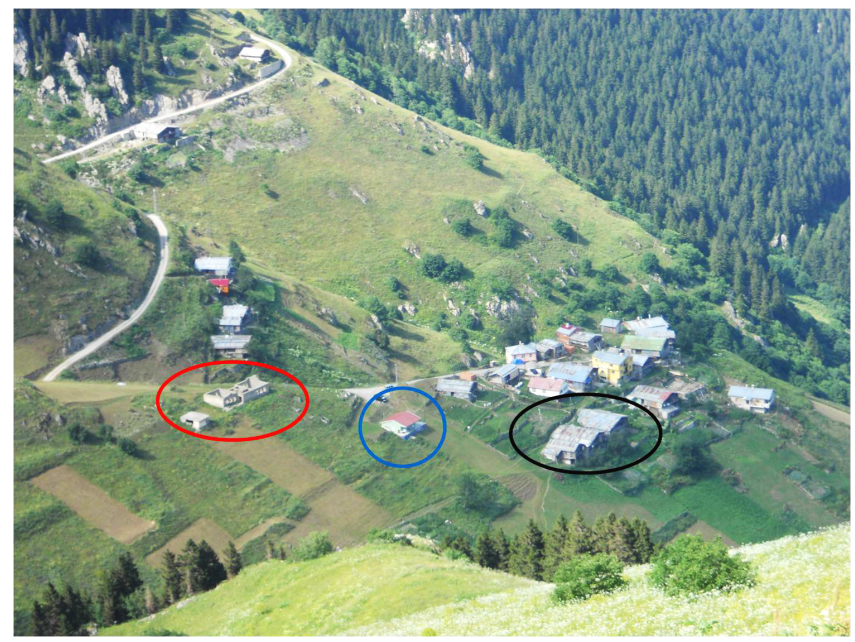

Fig. 5. Damaged school building (red ellipse) and houses (black ellipse) due to the 1981 avalanche; house indicated in blue circle constructed in 2004.

and wooden material) and the roof of the village's school building (constructed of bricks) (Fig. 5). A bowl-shaped release area, a channeled track and a run-out zone with slope angles of $8^{\circ}-11^{\circ}$, characterize the Yaylaönü avalanche path. All release zones were covered by grass vegetation with no bushes or large trees. The 1981 avalanche stopped around $2000 \mathrm{~m}$ after releasing, with a 6-7 $\mathrm{m}$ deposition height. There is no written information documenting this event.

\section{Numerical avalanche simulation software RAMMS}

The numerical avalanche dynamics simulation software RAMMS was developed at the WSL Institute for Snow and Avalanche Research SLF as a tool for engineers to calculate two-dimensional run out distances, flow velocities, flow heights, impact pressures, and flow paths of large-scale snow avalanches. It is a further development of the onedimensional avalanche simulation tool AVAL-1D (Christen et al., 2002). The simulations are based on the VoellmySalm friction model containing two parameters: the Coulomb friction $(\mu)$ and the velocity squared dependent turbulent friction ( $\xi$ ) (Voellmy, 1955; Salm et al., 1990). The model, calibrated with real-scale avalanche measurements from the Swiss SLF test site Vallée de la Sionne, requires high-quality DEM (Bühler et al., 2011, 2012) as well as defined release areas and release depths. It solves the depth-averaged equations governing avalanche flow with accurate second-order numerical schemes (Christen et al., 2010a). When used by experienced hazard experts combined with information on past avalanche events and field observations, RAMMS enables the calculation of different hazard scenarios as well as the back calculation of specific events (Bartelt et al., 2012; Christen et al., 2010b; Bühler et al., 2009). The software is commercially available and is used by avalanche experts and engineering offices to plan hazard mitigation projects around the world. Currently, a module for snow avalanche and one for debris flow simulations are available; modules for shallow landslides and rock falls are under development (http://ramms.slf.ch).

\section{DEM-based release zone identification}

Release zones for the Üzengili case were determined using a (geographical information systems) GIS-based digital elevation model DEM analysis. No snowpack or meteorological parameters are included in this analysis. Slope, planar curvature, roughness and size are the main parameters which are derived from the DEM in this procedure (Bühler et al., 2013). It is a further expansion of the algorithm developed by Maggioni and Gruber (2003) and works with high-spatial resolution DEM data sets ( $10 \mathrm{~m}$ resolution and better). In this study, a DEM resolution of $10 \mathrm{~m}$, a slope range of $28-60^{\circ}$ a curvature threshold of 3 and a ruggedness threshold of 0.03 were used. After a final plausibility check by an avalanche expert and a correction procedure, the release zones were used as input for the numerical simulation software RAMMS. Such an approach has the potential to be used for large-scale hazard mapping (Gruber and Bartelt, 2007).

We identified 10 potential release zones in the first step using the DEM-based algorithm, see Fig. 6. In the second step, we checked the release zones manually and selected and corrected the polygons, based on expert knowledge. Strong winds from the north and $70 \mathrm{~cm}$ of freshly fallen snow (over $10-20 \mathrm{~cm}$ of old snow) had been observed by the villagers just before the event. The release zones were located significantly higher than the Üzengili village. Therefore, based on the Swiss guidelines (Salm et al., 1990), we used a snow depth of $160 \mathrm{~cm}$ and included $50 \mathrm{~cm}$ of wind accumulation to calculate the release depths.

For the Yaylaönü event all information was collected in the field by interviewing villagers and observers. During the avalanche, strong winds from the south and more than $24 \mathrm{~h}$ of continuous snowfall $(90-100 \mathrm{~cm})$ were reported. Three main release zones were identified. Based on this information, the release depth was estimated to be around $160 \mathrm{~cm}$ (Fig. 7).

\section{Results and discussion}

\subsection{Applied scenarios}

In Üzengili, the avalanche occurred at 7.30 LT (local time) and according to villagers' observations came from the lefthand side slope (in the flow direction) and filled the track with a deposit of snow. Just a few minutes later a second avalanche came from the slope on the right-hand side, causing the damage, so we know that the two avalanches came just one after another. In order to corroborate the villagers' 

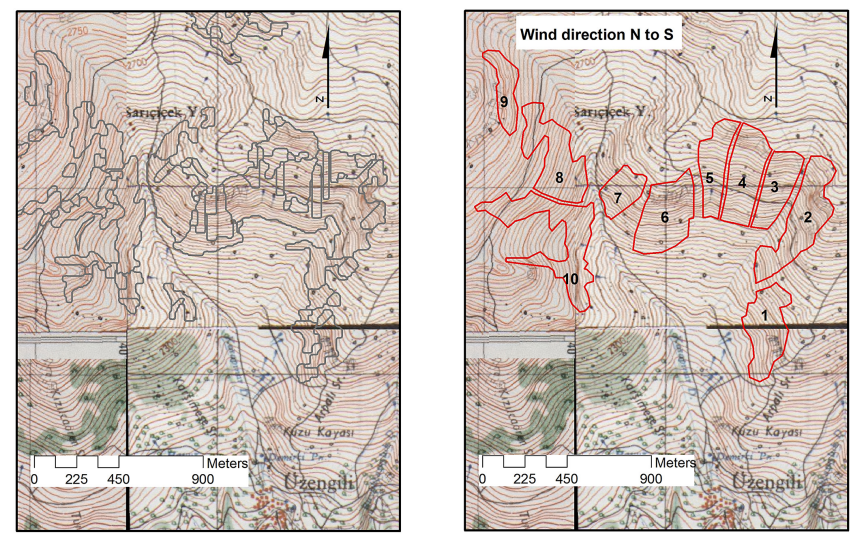

Fig. 6. Identified release zones by DEM-based release zone generation approach (left); corrected release zones to use in simulations at Üzengili (right) with a DEM resample of $10 \mathrm{~m}$, a curvature threshold of 3 and a roughness threshold of 0.03 .

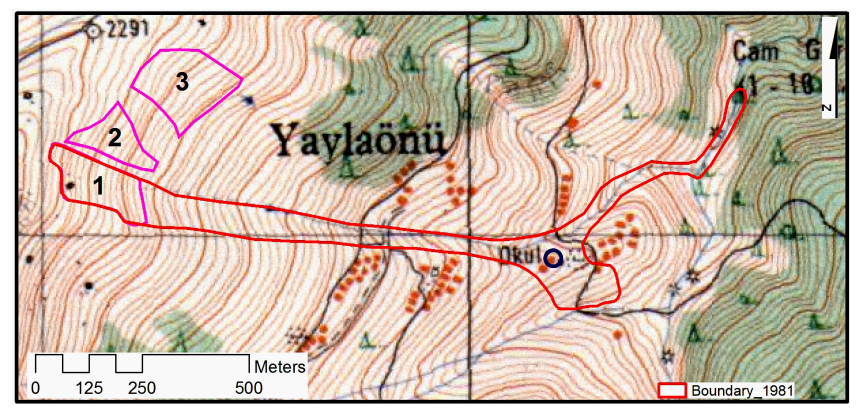

Fig. 7. Outlines of the 1981 avalanche event and potential release zones (damaged school indicated in blue circle, see Fig. 5).

statements with numerical avalanche simulations, we used six different elaborated scenarios (Table 1). RAMMS allows DEM modifications, for example, updating the track with a previous avalanche deposit. For scenarios 2-6, we made the DEM adaptation after releasing zone number 1 . Then we released the other zones over the adapted DEM to see the effect of filling the track by the first avalanche. We applied six different probable scenarios, but only scenario 3 was able to cause an event as big as had been observed; the results of scenario 3 are presented in the following sections.

At the Yaylaönü site, the avalanche occurred at $09.00 \mathrm{LT}$, so the eyewitnesses were clearly able to identify the release zone. The 1981 avalanche originated from release zone number 1, see Fig. 7. Release zone number 1 was leeward of the strong south-north winds and the snow had accumulated heavily. Release zones number 2 and 3 were located at the windward side and the wind caused the snow to drift from there to behind the northern ridge. Thus, only the avalanche release zone number 1 scenario was applied; the results are reported in the following sections.
Table 1. Applied scenarios (See Fig. 6).

\begin{tabular}{llll}
\hline Scenarios & \multicolumn{2}{c}{ Release zones } & Remarks \\
& First & Second & \\
\hline S1 & - & - & All released individually \\
S2 & 1 & $2-5$ & DEM adaptation procedures applied \\
S3 & 1 & $3-5$ & DEM adaptation procedures applied \\
S4 & $1-2$ & $3-5$ & DEM adaptation procedures applied \\
S5 & 1 & $6-7$ & DEM adaptation procedures applied \\
S6 & 1 & $8-10$ & DEM adaptation procedures applied \\
\hline
\end{tabular}

\subsection{Friction parameters}

In RAMMS friction parameters can be specified as constant (for the whole calculation domain) or variable. Constant values are recommended for a first attempt to quickly analyze the problem (Christen et al., 2010b). Variable friction parameters for the entire calculation domain are automatically calculated using GIS-based terrain analysis for different return periods and avalanche volume classes (RAMMS Manual, 2010).

In RAMMS, the dry coulomb friction $(\mu)$ and the velocity dependent turbulent friction $(\xi)$ depend on the avalanche volume, the return period and the terrain. We used values based on the calibration with avalanche events within the SLF realscale test site Vallée de la Sionne, in Switzerland. Because both events can be considered as extreme and the volumes have been large $\left(>60000 \mathrm{~m}^{3}\right)$ we have chosen corresponding friction values. The aim of this study was not to calibrate the friction parameters for Turkish avalanches. Thus, for both study areas constant values of $\mu$ and $\xi$ were used for the entire calculation domain. For the Üzengili avalanche site $\mu=$ 0.19 and $\xi=2100 \mathrm{~ms}^{-2}$ were selected. Because we had a channeled avalanche track at the Yaylaönü avalanche site, the parameters were selected as $\mu=0.24$ and $\xi=1500 \mathrm{~ms}^{-2}$, as suggested in the Swiss guidelines (Salm et al., 1990). The Swiss guidelines were developed for the analytical VoellmySalm model. These values were adapted for numerical simulation with AVAL-1D (Christen et al. 2002) and RAMMS. These adaptations are based on the back calculation of numerous large-scale avalanches in a dissertation at SLF (Gruber et al., 1998; Gruber, 1998, Gruber and Bartelt, 2007). The adapted $\mu$ and $\xi$ values are listed in Bartelt et al. (2010).

\subsection{Flow heights and impact pressures}

Üzengili avalanche site: at the Üzengili avalanche site, according to the statements of eyewitnesses, the deposition height was about $7-8 \mathrm{~m}$. This value may have occurred in some places due to the obstacle effect of buildings. When considering the comparably wide run-out zone, a deposition height of $3-5 \mathrm{~m}$ at the center part was thought to be reasonable. However, at the eastern part of the deposition zone much less deposition height simulated which is higher in the real situation. Contrary, at the downmost part of the 

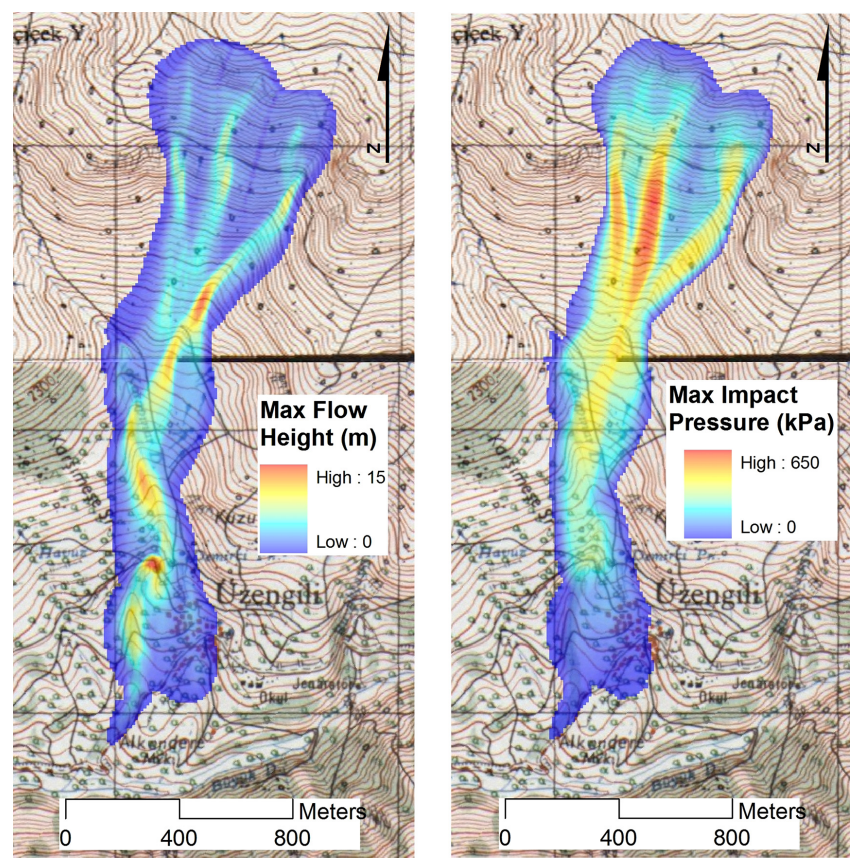

Fig. 8. Maximum flow height (left) and maximum impact pressure (right).

deposition zone, even no deposition observed a little bit of deposition simulated (Fig. 8). A sketch (Fig. 9) by the GDDA describing the location of damaged buildings by the avalanche is included and it is assumed that this sketch shows the boundary of the avalanche. Since no detailed information on flow velocity or impact pressure was available, the simulation result could not be verified. However, a pressure of $10-20 \mathrm{kPa}$ has been estimated at the mosque by visual interpretation on photographs which shows structural damages (Fig. 4), and corresponds well with the simulated avalanche results (M. Schaer, personal communication, 2012). Flow height and impact pressure for the entire avalanche track are given in Fig. 8. Furthermore, the impact pressure forces calculated at the mosque location are shown in Fig. 10.

Yaylaönü avalanche site: at the Yaylaönü avalanche site, the villagers' statements about a deposition height of 6-7 m seemed to be realistic. Due to a narrow, channeled run-out zone, simulation results also showed deposition to be around $7 \mathrm{~m}$ at the deposition zone, which complies with the villagers' statements (Fig. 11). In 1981 the avalanche damaged the school building by breaking doors and windows and uplifting the roof, but it was not completely destroyed. Maybe the damages at the building were caused by a powder cloud. A pressure of less than $1-2 \mathrm{kPa}$ on the dense part of the avalanche could have been seen at the edge of the school building and seems to be acceptable. The simulation results support this argument. A sketch based on villagers' statements drawing the outline of the 1981 avalanche (Fig. 7) corresponds to the outline of the modeled avalanche (compare

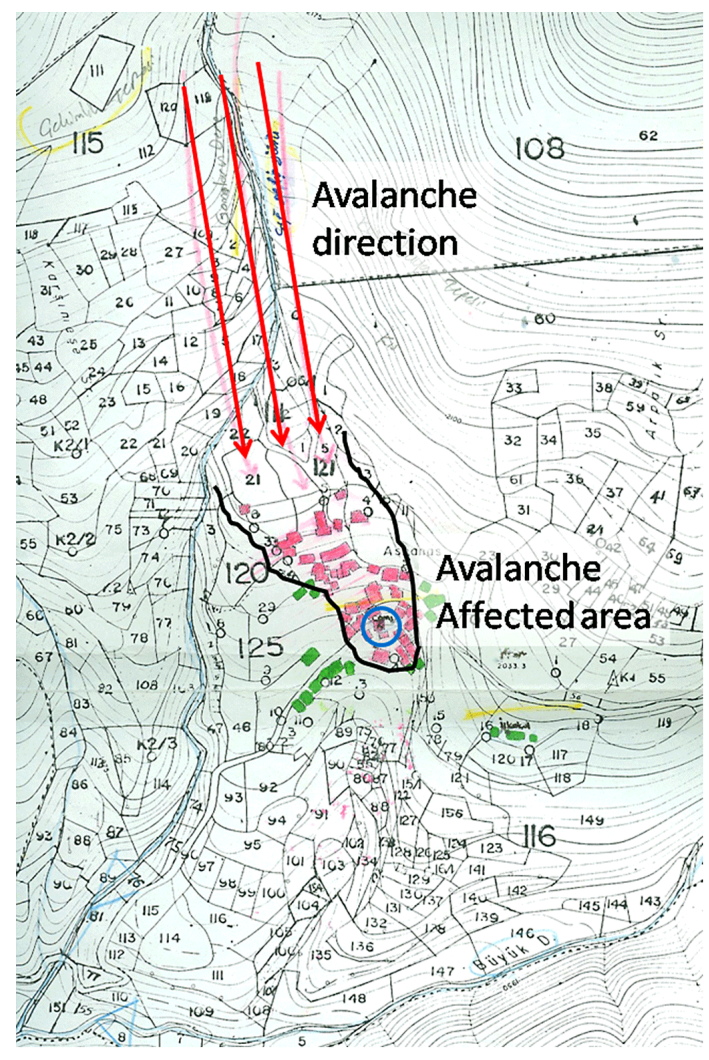

Fig. 9. Avalanche affected houses (red); non-affected houses (green); mosque indicated by blue circle, see Fig. 4 (Source: GDDA).

Fig. 7 and Fig. 11). Impact pressure for the entire avalanche track are given in Fig. 11; impact pressure forces calculated at the damaged school location are shown in Fig. 12.

\section{Conclusions}

Turkey is a fast developing country, with more than $78 \%$ of its territory in mountainous areas. According to information from the Ministry of Transportation, $15700 \mathrm{~km}$ of new double-lane highways have been constructed over the last ten years and there are plans to build another $15000 \mathrm{~km}$ of new railway lines by the year 2023. Furthermore, winter sport activities have been increasing in Turkey during the last decade. It can be inferred that the importance of avalanches as a major natural hazard in Turkey will increase substantially.

In Turkey, the proportion of avalanche fatalities of those who have died in their homes is very high (87\%) compared with European countries and North American; for example, in Switzerland and in the United States less than $5 \%$ of the people who have died in avalanches are killed in their homes. This is the result of the long history of great efforts in avalanche research, hazard mapping and mitigation measures established in these regions. 


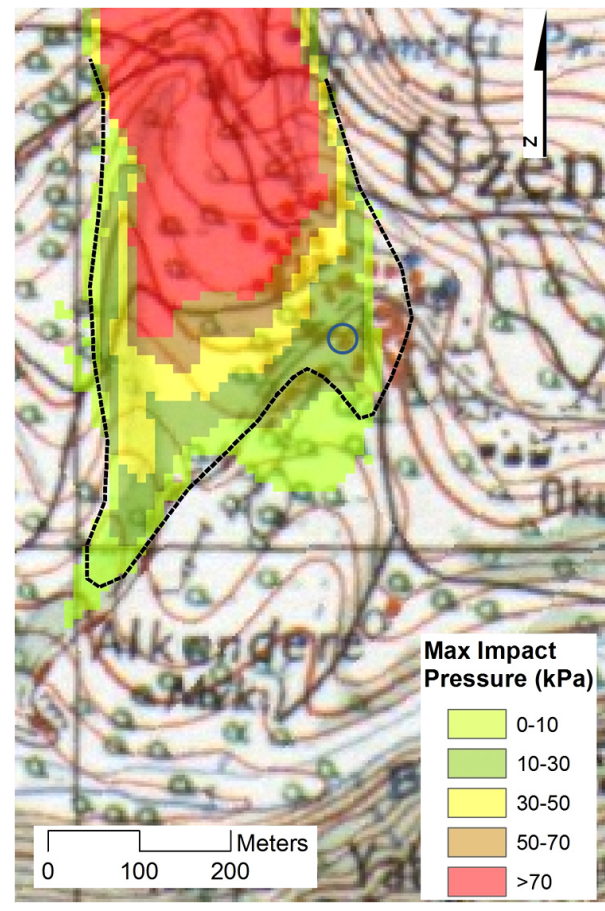

Fig. 10. Avalanche impact pressure at damaged mosque area (mosque indicated with blue circle, see Fig. 4; dashed black line indicates the outline of observed avalanche).

Avalanche mitigation requires a multidisciplinary approach. Thus in Turkey, a multidisciplinary organizational structure which includes foresters, GIS experts, civil engineers and geographers at the central and local offices of avalanche-prone areas are needed to improve the situation. Legislation gaps must be filled in order to outline a concrete definition of organizational duties and responsibilities. Avalanche mitigation needs the support of a strong R\&D department. Unfortunately, in Turkey not many scientists or researchers are involved in avalanche studies. Establishing an independent research institute would ensure success in meeting the needs of operational branches and in the training of research staff. Furthermore, it is necessary to obtain sufficient meteorological data reflecting high-mountain conditions. This could be achieved by setting up an organized alpine weather station network.

The Üzengili (Bayburt) and Yaylaönü (Trabzon) avalanches were selected to test the feasibility of using RAMMS in such cases. Even without meteorological data and the lack of exact release area information of the Üzengili avalanche, RAMMS produced realistic results. The DEM-based release generation is a big help but requires expert knowledge; using the generated release zones directly as input of RAMMS can be deceptive and cause unrealistic results.
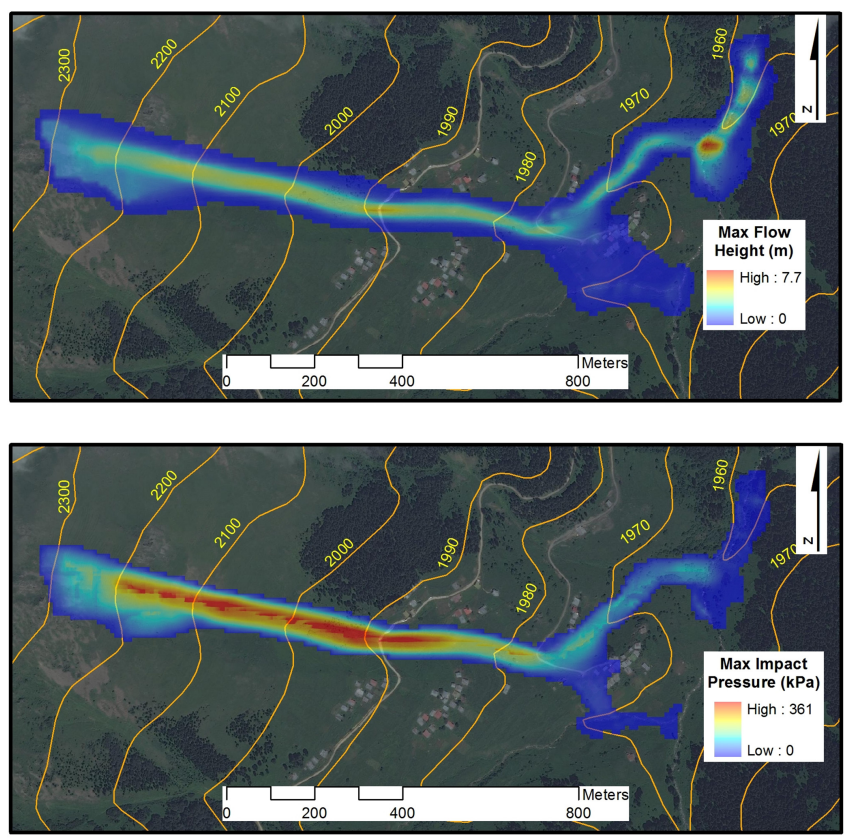

Fig. 11. Simulation result of Yaylaönü project area: maximum flow height (top) and maximum impact pressure (bottom).

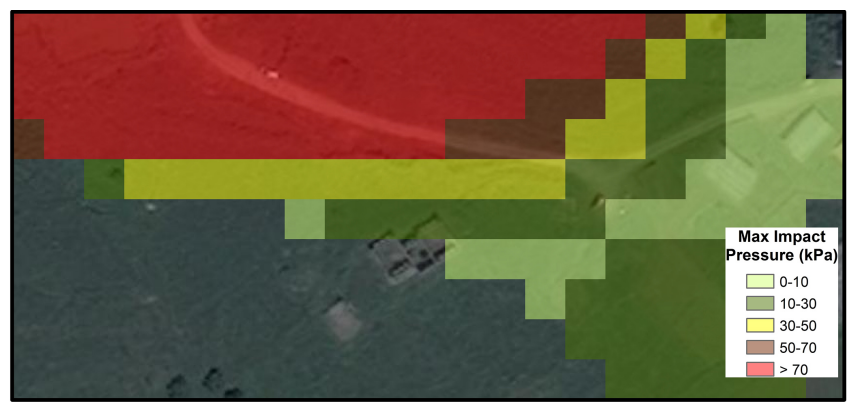

Fig. 12. Damaged school during 1981 avalanche; impact pressure forces of around $1-2 \mathrm{kPa}$.

We used default friction values with little modification in the Üzengili avalanche simulations, as recommended by the Gruber et al. (1998), Gruber (1998), Gruber and Bartelt (2007) and Bartelt et al. (2012). For the Yaylaönü avalanche site, we used the parameters for channeled avalanches which are recommended by the RAMMS Manual (Bartelt et al., 2010). Even though, RAMMS is calibrated for large-scale avalanches in Switzerland. It is very important to see that this model also works well in a climatically completely different regions such as Turkey with realistic results for our cases. This indicates the robustness and reliability of the Voellmy-Salm approach for avalanche simulation to improve hazard mapping and hazard zonation where such simulations are missing for other areas than for the European Alps. But users should be very careful in using and keep in mind some main limitation of dynamic models such as calibrating parameters, sensitivity analysis, problems orig- 
inated from event documentation and so on (Jamieson et al., 2008).

Although villagers in Üzengili claimed that the second avalanche had come from the right-hand side slope (in flow direction), simulation results did not agree with this statement. We concluded that the second avalanche originated from release zones number 3-5 of the left-hand side slope (see Fig. 6 and Table 1).

This study shows that based on the observations and estimations made in this paper, we assume that RAMMS can be help for hazard mitigation planning. The impact forces predicted by RAMMS at the mosque (Üzengili avalanche) and the school location (Yaylaönü avalanche) are in good agreement with the observed situation. Although generalization is not recommended, using RAMMS with expert knowledge for sparsely documented events can yield valuable information. Many countries with alpine regions exist, where no or very sparse historic avalanche information exists; as a result, it is interesting to read how the tools developed elsewhere can be applied and what limitations and problems occur. Furthermore, hazard mapping in remote regions is a demanding task. However, to do nothing is not an option in many regions. The application of numerical simulations can therefore be a big help by keeping in mind their limitations, necessity of good event documentation and expert opinions. This papers show how such a tool can be applied.

Edited by: R. Lasaponara

Reviewed by: two anonymous referees

\section{References}

Akçar, N. and Schlüchter, C.: Paleoglaciation in Anatolia: a schematic review and first results, Eiszeitalter und Gegenwart, 55, 102-121, 2005.

Atkins, D.: Ten years of avalanche deaths in the USA, 1999/2000 to $2008 / 2009$, International Snow Science Workshop 2010, Proceedings, Lake Tahoe, CA, 768-775, 2010.

Bartelt, P., Bühler, Y., Christen, M., Deubelbeiss, Y., Graf, C., and McArdell, B.:

RAMMS User Manual: Avalanche, SLF, Davos, http://ramms. slf.ch, 2010.

Bartelt, P., Bühler, Y., Buser, O., Christen, M., and Meier, L.: Modeling mass-dependent flow regime transitions to predict the stopping and depositional behavior of snow avalanches, J. Geophys. Res.-Earth Surf., 117, 1-28, 2012.

Bekereci, A., Küçük, Ö., and Çamalan, G.: The Föhn Effects in Forest Fires of Air Masses Affecting Turkey. 1st Meteorology Symposium, 27-28 May Ankara, Presentations Book, 83-95, 2010 (in Turkish).

Bozkurt, E.: Neotectonics of Turkey - A Synthesis, Geodinamica Acta, 14, 3-30, 2001.

Bühler, Y., Hüni, A., Christen, M., Meister, R., and Kellenberger, T.: Automated detection and mapping of avalanche deposits using airborne optical remote sensing data, Cold Reg. Sci. Technol., 57, 99-106, 2009.
Bühler, Y., Christen, M., Kowalski, J., and Bartelt, P.: Sensitivity of snow avalanche simulations to digital elevation model quality and resolution, Ann. Glaciol., 52, 72-80, 2011.

Bühler, Y., Marty, M., and Ginzler, C.: High Resolution DEM Generation in High-Alpine Terrain Using Airborne Remote Sensing Techniques, Transaction in GIS, 26, 635-647, 2012.

Bühler, Y., Kumar, S., Veitinger, J., Christen, M., Stoffel, A., and Snehmani: Automated identification of potential snow avalanche release areas based on digital elevation models, Nat. Hazards Earth Syst. Sci., 13, 1321-1335, doi:10.5194/nhess-13-13212013, 2013.

Christen, M., Bartelt, P., and Gruber, U.: AVAL-1D: An Avalanche Dynamics Program for the Practice, INTERPRAEVENT 2002 in the Pacific Rim, 2, 715-725, 2002.

Christen, M., Kowalski, J., and Bartelt, P.: RAMMS: Numerical simulation of dense snow avalanches in three-dimensional terrain, Cold Reg. Sci. Technol., 63, 1-14, 2010a.

Christen, M., Bartelt, P., and Kowalski, J.: Back calculation of the In den Arelen Avalanche with RAMMS: interpretation of model results, Ann. Glaciol., 51, 161-168, 2010b.

EEA (European Environment Agency): Europe's ecological backbone: recognizing the true value of our mountains.EEA Report No 6, Copenhagen, 2010.

Elibüyük, M. and Yılmaz, E.: Altitude steps and slope groups of Turkey in comparison with geographical regions and subregions, J. Geograph. Sci., 8, 27-55, 2010 (in Turkish).

Gruber, U., Bartelt, P., and Haefner, H.: Avalanche hazard mapping using numerical Voellmy fluid models, in: Proceedings of the Anniversary Conference 25 years of Snow Avalanche Research, edited by: Hestnes, E., Voss, 12-16 May 1998, Oslo, Norwegian Geotechnical Institute, 203, 117-121, 1998.

Gürer, I.: International cooperation for solving the avalanche problem in Turkey, Nat. Hazards, 18, 77-85, 1998.

Gruber, U.: Der Einsatz numerischer Simulationsmethoden in der Lawinengefahrenkartierung: Möglichkeiten und Grenzen. Dissertation, Geographisches Institut der Universitaet Zürich, 1998.

Gruber, U. and Bartelt, P.: Snow avalanche hazard modeling of large areas using shallow water numerical methods and GIS, Environ. Model. Software, 22, 1472-1481, 2007.

Gürer, I. and Naaim, M.: The Avalanche accident at Bayburt, Üzengili Located in North-Eastern Anatolia Türkiye on 18 January 1993, 2nd Avalanche Dynamics Workshop, InnsbruckAustria, 1993.

Gürer, I., Toprak F., and Ercan, S.: The avalanche accidents at Soğanlì Mountain located in North-Eastern Anatolia, Türkiye on 18 January 1993, in: 5th International Conference on Natural and Man-Made Hazards, HAZARDS-93, 29 August-3 September 1993, Quingdao, China, 1993.

Gürer, I., Tunçel, H., Yavaş, Ö.M., Erenbilge, T., and Sayın, A.: Snow Avalanche Incidents in North-Western Anatolia, Turkey during December 1992, Nat. Hazards, 11, 1-16, 1995.

Ives, J. D., Messerli, B., and Spiess, E.: Mountains in the World: A Global Priority, Carnforth-Parthenon, 1997.

Jamieson, B., Margreth, B., and Jones, A.: Application and limitatitons of dynamic models for snow avalanche hazard mapping. Proceedings of the International Snow Science Workshop 2008, Telluride, Colorado, US, 730-739, 2008.

Köse, N., Aydın, A., Akkemik, Ü., Yurtseven, and Güner, H. T.: Using tree-ring signals and numerical model to identify the snow 
avalanche tracks in Kastamonu, Turkey. Natural Hazards, 54, 435-449, 2010.

Kräuchi, N., Brang P., and Schönenberger, W.: Forests of mountainous regions: gaps in knowledge and research needs, For. Ecol. Manage., 132, 73-82, 2000.

Maggioni, M. and Gruber, U.: The influence of topographic parameters on avalanche release dimension and frequency, Cold Reg. Sci. Technol., 37, 407-419, 2003.

Price, M. and Butt, N.: Forests in Sustainable Mountain Development, IUFRO Research Series No. 5, 2000.

Salm, B., Burkard, A., and Gubler, H.: Berechnung von Fliesslawinen: eine Anleitung für Praktiker mit Beispielen, Mitteilung 47, Eidg. Institut für Schnee- und Lawinenforschung SLF Davos, 47, 1-37, 1990.

Schweizer, J. and Lütschg, M.: Characteristics of human-triggered avalanches, Cold Reg. Sci. Technol., 33, 147-162, 2001.
Sensoy, S.: The Mountains Influence On turkey Climate, Balwois Conference on Water Observation and Information System for Decision Support, Ohrid 25-29 May, 2004.

Viviroli, D., Dürr, H.H., Messerli, B., Meybeck, M., and Weingartner, R.: Mountains of the world, water towers for humanity: Topology, mapping, and global significance, Water Resour. Res., 43, 1-13, 2007.

Voellmy, A.: Über die Zerstörungskraft von Lawinen. Schweizerische Bauzeitung, Sonderdruck aus dem 73. Jahrgang (12, 15, 17,19 und 37), 1-25, 1955.

Zweifel, B., Techel, B., and Björk, C.: Who is involved in avalanche accidents. Proceedings, of International Snow Science Workshop 2012, Anchorage, Alaska, 234-239, 2010. 